\title{
ANALISA PERKEMBANGAN UMKM DI INDONESIA PADA TAHUN 2017 - 2019
}

\author{
TEGUH SANTOSA ${ }^{1}$, YENIASARI RIZKIA BUDI ${ }^{2}$ \\ $\underline{\text { teguh@ibm.ac.id }}{ }^{1}$, yeniasari@ibm.ac.id ${ }^{2}$ \\ Program Studi Ekonomi Pembangunan ${ }^{1}$ \\ Program Studi Akuntansi ${ }^{2}$ \\ Institut Bisnis Muhammadiyah Bekasi
}

\begin{abstract}
The development of economic growth is certainly supported by the increasing volume of goods and services that can provide prosperity for the community. Economic development can be seen from the increase in GDP regardless of whether the increase is smaller or larger than population growth. Micro, small and medium enterprises (UMKM) are one of the business units that have an important role in the development and growth of the country's economy. UMKM business growth is certainly an opportunity as a field to find work and income, with a lot of employment in UMKM showing that UMKM have a strategic role for the government in helping to reduce poverty and unemployment. The MSME sector has a large share of the Indonesian economy. Based on information obtained from the Ministry of Cooperatives and UMKM, in 2019 UMKM had a proportion of $99.9 \%$ of the total number of more than 65 million registered business units. The proportion of loans given to UMKM has always increased from 2017 to 2019 in accordance with the size of the business established. The largest contribution to PDB is provided by the micro-enterprise sector. The micro-enterprise sector annually contributes more than $25 \%$ to PDB compared to other sectors which are only able to contribute below $20 \%$.
\end{abstract}

\section{Keywords: UMKM, Gross Domestic Product, and Proportion of Credit}

\section{PENDAHULUAN}

Pada dunia bisnis maupun usaha tentu saja menginginkan usahanya dapat terus berkembang. Mempertahankan kelangsungan usaha bisnis sangat tidak mudah, tentunya memerlukan beberapa strategi yang harus diterapkan agar lebih efektif dan efisien. Perkembangan pertumbuhan ekonomi tentunya didukung dengan bertambahnya volume peningkatan atas barang dan jasa yang dapat memberikan kemakmuran masyarakat (Sukirno, 1994). Pembangunan ekonomi dapat dilihat dari kenaikan GDP tanpa memandang apakah kenaikan tersebut lebih kecil maupun lebih besar dari pertumbuhan penduduk.

Usaha mikro, kecil dan menengah (UMKM) merupakan salah satu unit usaha yang memiliki peran penting dalam perkembangan dan pertumbuhan perekonomian negara. Sektor UMKM membantu dalam menyerap angkatan kerja yang tidak terserap dalam dunia kerja. Pertumbuhan usaha UMKM tentunya menjadi kesempatan sebagai ladang untuk 
mencari kerja dan pendapatan, dengan banyak penyerapan tenaga kerja pada UMKM menunjukkan bahwa UMKM memiliki peran strategis bagi pemerintah dalam membantu mengurangi jumlah kemiskinan dan pengangguran. Berdasarkan informasi yang dilansir melalui (JawaPos.com), sektor usaha mikro kecil dan menengah (UMKM) menjadi kontributor penting dalam menyumbang produk domestik bruto (PDB), dimana sepanjang tahun 2019 sektor UMKM menyumbang $60 \%$ PDB dan berkontribusi dalam ekspor sebesar $14 \%$.

Di Indonesia terdapat beberapa peraturan yang mengatur UMKM dimana tertuang dalam Undang-Undang No. 20 Tahun 2008, menyebutkan bahwa "perusahaan kecil yang dimiliki dan dikelola seseorang dengan jumlah pendapatan tertentu". Berikut kriteria UMKM yang ditetapkan berdasarkan dengan aset dan omset.

Tabel 1

Kriteria UMKM

\begin{tabular}{|c|c|c|}
\hline \multirow[b]{2}{*}{ Ukuran Usaha } & \multicolumn{2}{|c|}{ Kriteria } \\
\hline & $\begin{array}{c}\text { Aset } \\
\text { (tidak termasuk tanah \& bangunan tempat usaha) }\end{array}$ & $\begin{array}{c}\text { Omzet } \\
\text { (dalam } 1 \text { tahun) }\end{array}$ \\
\hline Usaha Mikro & Maksimal Rp 50 juta & Maksimal Rp 300 juta \\
\hline Usaha Kecil & Lebih dari Rp 50 juta - Rp 500 juta & Lebih dari Rp 300 juta - Rp 2,5 miliar \\
\hline Usaha Menengah & Lebih dari Rp 500 juta - Rp 10 miliar & Lebih dari Rp 2,5 miliar - Rp 50 miliar \\
\hline Usaha Besar & Lebih dari Rp 10 miliar & Lebih dari Rp 50 miliar \\
\hline
\end{tabular}

Sumber: UU No.20/2008 tentang Usaha Mikro, Kecil, dan Menengah

Seiring dengan perkembangan waktu peran dari UMKM menjadi lebih penting sebagai penopang pertumbuhan perekonomian dalam negeri. Sektor UMKM memiliki potensi yang besar, namun dalam kenyataannya UMKM masih mengalami berbagai hambatan baik dalam internal maupun eksternal. Terkait dengan hambatan secara internal seperti sumber daya manusia yang kurang kompeten, kurangnya pendanaan modal, lemahnya jaringan usaha. Sedangkan hambatan eksternal yang bisa dialami seperti, persaingan usaha, kesulitan dalam memasarkan produk dan jasa, terbatasnya akses pasar, terbatasnya sarana dan prasarana serta iklim yang kurang mendukung.

\section{TINJAUAN PUSTAKA}

\section{Pengertian UMKM}

Berdasarkan Undang-undang Dasar 1945 yang dikuatkan oleh TAP MPR No. XVI/MPR-RI/1998 mengenai "Politik Ekonomi dalam Rangka Pelaksanaan Demokrasi Ekonomi, Usaha Mikro, Kecil dan Menengah" perlu diberdayakan sebagai bagian dari integral ekonomi rakyat yang memiliki kedudukan, peran dan potensi strategis demi mewujudkan struktur perekonomian yang semakin berkembang, seimbang, dan berkeadilan. Alma (2010), mengungkapkan bahwa usaha mikro merupakan usaha yang didirikan oleh individu atau keluarga yang belum memiliki izin usaha secara lengkap. 
Undang-undang No. 9 Tahun 1999 yang telah diubah ke Undang-undang No. 20 Tahun 2008 Pasal 1 UMKM memiliki beberapa pengertian antara lain :

1) Usaha mikro merupakan usaha yang dimiliki oleh perorangan, dimana usaha tersebut telah memenuhi kriteria usaha yang diatur dalam Undang-undang.

2) Usaha kecil merupakan usaha yang berdiri sendiri, dimana usaha tersebut dilakukan oleh perorangan atau badan usaha yang bukan bagian dari anak perusahaan dari skala menengah sampai besar.

3) Usaha menengah merupakan usaha ekonomi yang berdiri sendiri, usaha menengah ini hampir sama dengan usaha kecil, hanya jumlah kekayaan bersih atau hasil penjualan tahunan yang dimiliki sesuai dengan yang telah diatur dalam Undang-undang.

4) Usaha besar merupakan usaha ekonomi yang dilakukan oleh badan usaha, dimana jumlah kekayaan bersih atau penjualan tahunannya melebihi usaha ekonomi menengah. Usaha ini dapat meliputi usaha nasional milik negara atau swasta, maupun usaha asing yang dilakukan di Indonesia.

5) Dunia usaha diartikan sebagai usaha mikro, kecil, menengah dan usaha besar yang memiliki kegiatan usaha di Indonesia dan berdomisili di Indonesia.
Berdasarkan beberapa pengertian diatas, maka dapat ditarik kesimpulan, bahwa usaha mikro, kecil, dan menengah merupakan usaha yang didirikan oleh individu atau sekelompok orang yang bersama-sama membangun usaha ekonomi untuk meningkatkan pendapatan, namun dengan izin usaha yang belum terpenuhi secara keseluruhan.

\section{Kriteria UMKM}

Menurut Pasal 6 Undang-undang No. 20 Tahun 2008 mengenai kriteria UMKM tentang permodalan antara lain:

1) Kriteria usaha mikro

a. Mempunyai kekayaan bersih paling banyak Rp. 50 Juta tidak termasuk aset yang dimiliki (tanah dan bangunan).

b. Hasil penjualan tahunan yang di dapat paling banyak Rp. 300 Juta.

2) Kriteria usaha kecil

a. Mempunyai kekayaan bersih lebih dari Rp. 50 Juta sampai paling banyak Rp. 500 Juta tidak termasuk aset tetap (tanah dan bangunan).

b. Hasil penjualan tahunan yang didapat lebih dari Rp. 300 Juta sampai paling banyak sebesar Rp. 2,5 M.

3) Kriteria usaha menengah

a. Mempunyai kekayaan bersih lebih dari Rp. 500 Juta dengan kekayaan paling banyak sampai dengan Rp. 10 M tidak termasuk aset yang dimiliki (tanah dan bangunan).

b. Hasil penjualan tahunan yang dimiliki lebih dari Rp. 2,5 M dan hasil penjualan paling banyak diterima sebesar Rp. 50 M. 


\section{Kebijakan Pemerintah}

UMKM di Indonesia menjadi salah satu bagian penting dalam sistem perekonomian, karena jumlah UMKM di Indonesia lebih banyak dibandingkan dengan industri berskala besar. Hal tersebut tentunya berdampak pada penyerapan lebih banyak tenaga kerja dan mempercepat jalannya pemerataan peningkatan pembangunan. Pentingnya UMKM pada sistem perekonomian di Indonesia sudah selayaknya sektor UMKM menjadi perhatian dan mendapatkan perlindungan terkait dengan kegiatan operasional dan pengembangannya.

Beberapa pengaturan telah dikeluarkan oleh pemerintah untuk melindungi sektor UMKM salah satunya pada Pasal 5 ayat 1 , Pasal 20, Pasal 27 ayat 2, Pasal 33. Begitu Pula yang tertuang dalam Undang-undang No. 9 Tahun 1995 dengan disahkan oleh Ketetapan MPR Republik Indonesia Nomor. XVI/MPR/1998, mengenai "Politik Ekonomi dalam rangka Demokrasi Ekonomi, Usaha Mikro, Kecil, dan Menengah yang perlu diberdayakan sebagai bagian dari integral ekonomi rakyat yang mempunyai kedudukan, peran, serta potensi strategis untuk mewujudkan struktur perekonomian nasional yang seimbang, berkembang dan berkeadilan. Pemerintah mempunyai harapan dengan dikeluarkannya kebijakan instrumen kebutuhan pengembangan UMKM.

\section{METODOLOGI PENELITIAN}

Penelitian ini berkaitan dengan UMKM hanya mendeskripsikan dan memberikan solusi atas permasalahan melalui studi literatur yang saling terkait. Data yang diperoleh berasal dari Kementerian Koperasi dan Usaha Kecil maupun berasal dari data Badan Pusat Statistik (BPS).

\section{PEMBAHASAN}

Sektor UMKM memiliki proporsi pangsa yang besar dalam perekonomian Indonesia. Berdasarkan informasi yang diperoleh dari Kementerian Koperasi dan UMKM, pada tahun 2019 UMKM memiliki proporsi sebesar 99,9\% dari jumlah total 65 juta lebih unit usaha yang terdaftar. Melihat dari tingginya nilai proporsi tersebut dapat terlihat bahwa peran UMKM sangat membantu dalam menopang kemajuan perekonomian di Indonesia, karena mayoritas adalah usaha berskala kecil sehingga tidak terlalu bergantung dengan jumlah modal yang besar maupun pinjaman dari luar. Usaha mikro ini juga merupakan usaha yang tidak terlalu merasakan dampak dari fluktuasi nilai tukar. 
Tabel 2

Perkembangan UMKM dan Usaha Besar di Indonesia Tahun 2016-2019

\begin{tabular}{|c|c|c|c|}
\hline Keterangan & $\mathbf{2 0 1 7}$ & $\mathbf{2 0 1 8}$ & $\mathbf{2 0 1 9}$ \\
\hline Usaha Mikro & $98,70 \%$ & $98,68 \%$ & $98,67 \%$ \\
\hline Usaha Kecil & $1,20 \%$ & $1,22 \%$ & $1,22 \%$ \\
\hline Usaha Menengah & $0,09 \%$ & $0,09 \%$ & $0,10 \%$ \\
\hline Usaha Besar & $0,01 \%$ & $0,01 \%$ & $0,01 \%$ \\
\hline
\end{tabular}

Sumber : Kementerian Koperasi dan Usaha Kecil Menengah

Berdasarkan data pada tabel diatas dapat terlihat bahwa perkembangan usaha kecil dari tahun 2017 - 2019 mengalami penurunan di setiap tahunnya, walaupun dari data tersebut terlihat bahwa penurunan yang terjadi pada sektor usaha mikro tidak terlalu drastis hanya sebesar 0,01 - 0,02 persen per tahun. Pada sektor Usaha Kecil jika dilihat dari data tabel tersebut mengalami kenaikan pada tahun 2018 sebesar $0,02 \%$ dari tahun sebelumnya, sedangkan pada tahun 2019 terlihat konstan namun tidak mengalami penurunan. Pada sektor Usaha Menengah mengalami peningkatan sebesar $0,01 \%$ pada tahun 2019, sedangkan ada dua tahun sebelumnya cenderung konstan. Sedangkan untuk sektor Usaha Besar selama tiga tahun berturut-turut tidak mengalami peningkatan maupun penurunan (cenderung konstan), hal tersebut mungkin terjadi belum bertambahnya jenis usaha besar atau belum terdaftarnya beberapa jenis usaha yang tergolong besar.

Tabel 3

Proporsi Kredit UMKM Terhadap Total Kredit

(Dalam Triliun Rupiah)

\begin{tabular}{|c|c|c|c|}
\hline Keterangan & $\mathbf{2 0 1 7}$ & $\mathbf{2 0 1 8}$ & $\mathbf{2 0 1 9}$ \\
\hline Usaha Mikro & 221,41 & 251,34 & 277,23 \\
\hline Usaha Kecil & 282,78 & 312,07 & 332,12 \\
\hline Usaha Menengah & 438,2 & 469,24 & 488,79 \\
\hline
\end{tabular}

Sumber : Badan Pusat Statistik

Berdasarkan data yang terdapat dalam tabel 3 diatas, dapat terlihat besarnya proporsi kredit yang diberikan kepada UMKM selama tahun 2017 - 2019. Besaran proporsi yang diberikan tergantung pada besarnya jenis usaha yang didirikan, proporsi kredit paling besar diberikan pada sektor menengah dengan jumlah kredit melebihi 400 triliun rupiah per tahun. Dari data tersebut juga terlihat bahwa proporsi kredit yang diberikan kepada UMKM selalu meningkat dari tahun 2017 hingga 2019 
sesuai dengan besaran usaha yang didirikan. Melihat besarnya proporsi kredit yang diberikan kepada sektor UMKM kita optimis bahwa UMKM akan mampu tumbuh dan berkembang dan dapat bersaing di kancah internasional.

Tabel 4

Perkembangan UMKM Terhadap Sumbangan PDB atas Dasar Harga Konstan

(Dalam Miliar)

\begin{tabular}{|c|c|c|c|c|c|c|}
\hline \multirow{2}{*}{ Keterangan } & \multicolumn{2}{|c|}{2017} & \multicolumn{2}{c|}{2018} & \multicolumn{2}{c|}{2019} \\
\cline { 2 - 7 } & Jumlah & Pertumbuhan & Jumlah & Pertumbuhan & Jumlah & Pertumbuhan \\
\hline Usaha Mikro & 2.804 .585 & $29,51 \%$ & $2.927 .890,5$ & $29,29 \%$ & 3.701 .368 & $30,07 \%$ \\
\hline Usaha Kecil & $1.272 .701,4$ & $13,39 \%$ & $1.355 .705,7$ & $13,56 \%$ & $1.536 .961,1$ & $12,49 \%$ \\
\hline Usaha Menengah & $1.368 .277,9$ & $14,40 \%$ & $1.437 .551,9$ & $14,38 \%$ & $1.795 .817,7$ & $14,59 \%$ \\
\hline
\end{tabular}

Sumber : Badan Pusat Statistik

Berdasarkan data dari tabel tersebut terlihat bahwa sumbangan UMKM terhadap PDB ke negara mengalami fluktuasi. Pada sektor usaha mikro dilihat dari pertumbuhan sumbangan dari tahun 2017 - 2019 mengalami fluktuasi, sumbangan PDB terbesar usaha mikro terhadap PDB terjadi pada tahun 2019 dengan tingkat sumbangan sebesar 30,07\% dan sumbangan terendah pada tahun 2018 dengan tingkat sumbangan sebesar $29,29 \%$.

Pada sektor usaha kecil sumbangan terhadap PDB juga mengalami fluktuasi di setiap tahunnya, sumbangan terbesar terjadi pada tahun 2018 yaitu sebesar 13,56\%. Sedangkan sumbangan terendah terjadi pada tahun 2019 yaitu sebesar 12,49\%, jika dilihat dari proporsi pemberian kredit pada tahun 2019 mendapatkan tingkat peminjaman kredit paling besar yang dimana seharusnya dapat menyumbang terhadap PDB juga lebih besar dibandingkan dengan tahun-tahun sebelumnya. Faktor tersebut dapat terjadi karena berkurangnya pendapatan yang diterima di sektor usaha kecil yang mengalami penurunan dalam kinerjanya. Penurunan tersebut dapat terjadi karena kurangnya strategi pemasaran dan pengembangan produk yang lebih inovasi yang mengakibatkan berkurangnya daya tarik konsumen terhadap produk yang ditawarkan pada usaha kecil tersebut.

Pada sektor usaha menengah sumbangan terhadap sektor PDB juga mengalami fluktuasi, namun pada sektor ini tidak memberikan sumbangan yang besar, padahal jika dilihat dari tingkat proporsi pemberian kredit sektor menengah ini mendapatkan pemberian paling besar dibandingkan dengan 2 sektor sebelumnya. Persaingan bisnis serta desakan dari sektor ekonomi dapat membuat ruang lingkup usaha menjadi lebih sempit dan terbatas.

Jika dilihat kembali, sumbangan terhadap PDB terbesar diberikan oleh sektor usaha mikro. Sektor usaha mikro pada setiap tahunnya menyumbang lebih dari $25 \%$ terhadap PDB dibandingkan dengan sektor 
lain yang hanya mampu menyumbang dibawah 20\%. Dengan pemberian bantuan kredit yang kecil bukan berarti tidak bisa berkontribusi terhadap PDB, hal tersebut dibuktikan oleh sektor usaha mikro dengan adanya usaha dan pangsa pasar yang tinggi, maka sektor ini akan dapat berkembang lebih baik lagi dan akan dapat membantu perekonomian negara. Perhatian dan dukungan yang diberikan juga tentu mempengaruhi semangat juang para pelaku usaha mikro ini agar dapat terus berkembang, dimudahkan jalannya dalam segala pengurusan izin usaha.

\section{KESIMPULAN}

\section{Kesimpulan}

Berdasarkan dari data-data yang diperoleh perkembangan sektor UMKM sangat mempengaruhi perekonomian Indonesia, dimana penyumbang dan kontribusi terbesar terhadap PDB berasal dari sektor UMKM. Dimana pada sektor ini mayoritas adalah para pelaku usaha mikro kecil dimana mereka tidak tergantung pada modal yang besar serta pinjaman dari luar, dengan saat nilai tukar mengalami fluktuasi dampak tersebut tidak begitu dirasakan oleh pelaku usaha mikro kecil ini. Pemberian bantuan kredit yang diberikan kepada sektor UMKM dari tahun 2017 2019 yang terus meningkat dimana melebihi 400 Triliun Rupiah, dari jumlah besaran proporsi kredit yang diberikan tersebut bisa diartikan bahwa pemerintah sangat mendukung perkembangan sektor UMKM ini, dengan harapan agar sektor ini dapat terus berkembang dan menjadi bisnis yang dapat menopang perekonomian di Indonesia.

\section{Saran}

Dukungan dalam segala bidang tentunya sangat dibutuhkan oleh sektor UMKM ini, salah satunya kemudahan pembuatan izin pelaku usaha. Disamping itu untuk pemerintah sebaiknya lebih memperhatikan perkembangan sektor UMKM, memberikan keahlian manajerial dan pemasaran strategis untuk perkembangan bisnisnya. Dengan begitu maka kita optimis bahwa sektor UMKM dapat menembus kancah internasional, yang tentunya hal tersebut akan berdampak pada perekonomian Indonesia. 


\section{DAFTAR PUSTAKA}

Yuli Rahmini, S. 2017. Perkembangan UMKM (Usaha Mikro, Kecil dan Menengah) Di Indonesia. Jurnal Ilmiah Cano Ekonomos.

Undang-Undang No. 20 Pasal 1 dan 6 Tahun 2008.

http://www.hukumonline.com/pusatdata/download/fl56041/node/28029

https://kemenkopukm.go.id/data-

umkm/?SQvaONaKRL88GVOWT55WGc7oCWKKlqX36JUKWvVo7UmDp1Z8wU

(Diakses pada tanggal 8 Juni 2021)

https://www.jawapos.com/ekonomi/16/01/2020/akumindo-yakin-kontribusi-umkm-tahun-inicapai-rp-2-3945-triliun/ (Diakses pada tanggal 10 Juni 2021)

https://www.ukmindonesia.id/baca-artikel/62 (Diakses pada tanggal 10 Juni 2021)

https://pascasarjanafe.untan.ac.id/wp-content/uploads/2021/01/35.pdf (Diakses pada tanggal 12 Juni 2021)

https://www.bps.go.id/indikator/indikator/view_data/0000/data/1192/sdgs_8/1 (Diakses pada tanggal 14 Juni 2021) 